\title{
Assessment of the use of partographs in the region of Analamanga
}

\author{
Julio El-C Rakotonirina ${ }^{1}$, Candy Holy Randrianantenainjatovo ${ }^{2}$, Barbara Elyan Edwige \\ Vololonarivelo $^{2 *}$, Rabenaivo Dorasse ${ }^{2}$, Jean de Dieu Marie Rakotomanga ${ }^{1}$, \\ Andrianampanalinarivo Hery Rakotovao ${ }^{2}$
}

\author{
${ }^{1}$ Institut National de Santé Publique et Communautaire, BP 176 Befelatanana, Antananarivo 101, Madagascar \\ ${ }^{2}$ Faculté de Médecine d'Antananarivo, Antananarivo 101, Madagascar
}

Received: 16 April 2013

Accepted: 10 May 2013

*Correspondence:

Dr. Barbara Elyan Edwige Vololonarivelo

E-mail: barbara1elyan@gmail.com

(C) 2013 Rakotonirina JEC et al. This is an open-access article distributed under the terms of the Creative Commons Attribution Non-Commercial License, which permits unrestricted non-commercial use, distribution, and reproduction in any medium, provided the original work is properly cited.

\begin{abstract}
Background: Maternal mortality is associated with an ever-worrying trend in Madagascar. The partograph, set up by the WHO, is topical when it comes to maternal and child mortality-reducing strategies, especially in developing countries. This study assesses the effect of partograph use on maternal and neonatal mortality in maternity wards of ten basic health centres (BHC) and three hospitals located in the districts of Avaradrano, Atsimondrano, Ambohidratrimo, including the district hospital (DH) of Ambohidroa.

Methods: Across-sectional survey was conducted in selected districts, using parturients' medical records during year 2010. Data were derived from the partographs of women meeting the following criteria: a spontaneous onset of labour, an uniparous pregnancy, a term birth, a foetal cephalic presentation, with no extra complication.

Results: Neither maternal nor neonatal death was found where a partograph has been used. Partograph use rate is $64.8 \%$. The main reasons for not using partographs include absence of training and lack of skilled health personnel. 128 abnormalities were identified with a correct management rate of $60.9 \%$.

Conclusions: Although implementation of the partograph appears to be easy and inexpensive, its use still collides with huge difficulties. It requires a qualified aid and a suitable environment to have a positive and significant impact on maternal and perinatal mortalities related to birth.
\end{abstract}

Keywords: Partograph, Maternal and Neonatal Mortalities, Analamanga-Madagascar

\section{INTRODUCTION}

In Africa, 30 millions pregnancies are expected every year, yet 250,000 maternal deaths still occur. Out of 1 million newborn deaths, more than 300,000 happen during labour. ${ }^{1}$ Compared with occidental women, those from developing countries have a hundred times more exposure to pregnancy-related complications: there is an average 450 women deaths per 100,000 live births. ${ }^{2,3,4}$ Despite political commitment and efforts emanating from all actors, maternal and neonatal mortalities indicators show high ratios. ${ }^{5}$ As for Madagascar, maternal mortality trend remains worrisome: from 469/100,000 live births in $2003,{ }^{6}$ it rose up to $498 / 100,000$ in $2008 .^{7}$ Whereas neonatal mortality trend appears to be more encouraging: ratios decreased from 59/1,000 live births to 48/1,000 in 2008. , $^{6,}$ Aware of those problems and of the avoidable feature of these deaths in most cases, the WHO and its partners have implemented a monitoring tool, the partograph, in order to find out parturients' labour progress abnormalities in developing countries, including Madagascar. The partograph is a simple sheet of paper: it is the graphic recording of labour progress, delivery, as well as subsequent maternal and foetal monitored data. ${ }^{8}$ 
But could it hold a more important role than an electronic device? ${ }^{9}$ Thus, this study aims to identify factors contributing to the accurate use of the partograph in the health facilities, and to determine the impact of its use on maternal death and neonatal complications.

\section{METHODS}

A cross-sectional study was conducted during twelve months, from January, $1^{\text {st }}$ to December $31^{\text {st }}$ in 2010. Thirteen health facilities (10 Basic Health Centres (BHC) and 3 District Hospitals (DH)) were included. They have been selected because of their strategic and suburban context in care taking, the referral system connecting them, and an activity rate of 20 or more deliveries monthly. In these health facilities, 38 health care providers attending births were interviewed and 494 partographs were studied.

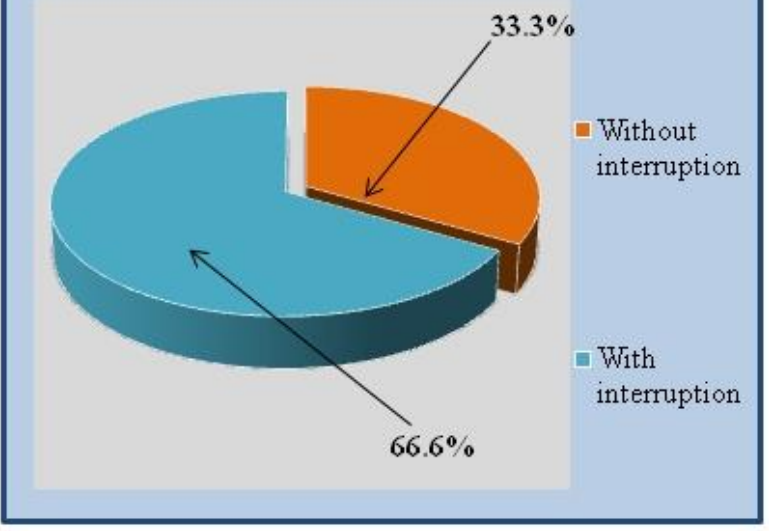

Figure 1: Distribution of selected cases by type of health centre.

Cases held to collect data include the following: a spontaneous onset of labour, an uniparous pregnancy, a term birth, a foetal cephalic presentation, with no extra complication. Ten per cent of medical records have been selected using the random sampling approach. ${ }^{10}$ All of health care providers who have attended births in the selected health facilities were enrolled. For each case, the following variables were considered: Birth place (peripheral or central service), Parity, Mother's height, Cervix dilation upon admission, Level of foetal presentation, Time elapsed since rupture of membranes, Vaginal examinations upon admission, latent phase duration, Shifting of the alert line to the right, dilation according to movement of alert line, Presentation level according to movement of alert line, Labour stimulation and progress, Duration of first and second stages of labour, Approach held when dilation line shifts to the right of the alert line or when action line has been reached or crossed, Delivery method, Dystocia, Uterine rupture, Partograph position at the moment of delivery, Neonatal outcome, Postpartum haemorrhage, Hyperthermia.

\section{RESULTS}

\section{General characteristics}

According to inclusion criteria, 13 health facilities (10 BHC and $3 \mathrm{DH}$ ) were selected in this study. In these facilities, 38 health care providers attending births were interviewed and 494 parturients' partographs were studied.

Young women aged 20 to 24 comprise the majority $(34.2 \%)$ of all age brackets proportions in our study. From the 494 parturients' medical records, we outlined that 483 $(97.7 \%)$ parturients are 1.50 metres tall or more, while 11 (2.3\%) are less than 1.50 metres tall. Among the latter, 4 cases belong to the 15 to 19 years old age bracket and 4 other cases belong to the 20 to 24 years old age bracket. A high proportion of midwives and nurses attend births ( midwives $=79.3 \%$, nurses $=83.3 \%$ ), wheresoever their site of work might be. Whereas physicians, particularly those who work in $\mathrm{DH}(7.1 \%)$, rarely attend births. Interviewing the health care providers let us identify that $18.4 \%$ of them do not know the definition of a partograph.

\section{Estimation of partograph use level and analysis of factors promoting its accurate use}

One out of thirteen health facilities does not use the partograph, though forms are available. Figure 2 shows that eight $(66.6 \%)$ out of the twelve facilities using the partograph knew a stock shortage during an average period of 60 days.

In BHC, absence of training and lack of health care personnel were reported as the main reasons for not using the partograph. On the contrary, in DH, the extra work and the unconsciousness of the benefits of partograph use were mostly cited.

Among the 494 random sample partographs (basis of the analysis), 372 were accurately filled, giving us an accurate use rate of $75.3 \%$. In DH, partograph accurate use rate is significantly higher than the rates found in BHC (83.6 vs. $72.9, \mathrm{p}=0.021$ ).

\section{Screening rate of abnormalities and related managements}

The 494 studied partographs allowed us to identify 128 abnormalities during labour, among which 63 in BHC and 65 in $\mathrm{DH}$. The screening rate of abnormalities in BHC is significantly lower (16.4 vs. 59.0, p < 0.001).

Abnormalities frequently identified by the health care providers comprise prolonged active phase, abnormalities of uterine contractions, maternal haemorrhage on delivery of the placenta, and dystocia.

In BHC, $47.6 \%$ of abnormalities (30 out of 63 ) were correctly managed. Correct management rate in $\mathrm{DH}$ is significantly higher $(73.8 \mathrm{Vs} 47.6, \mathrm{p}=0.002)$. 


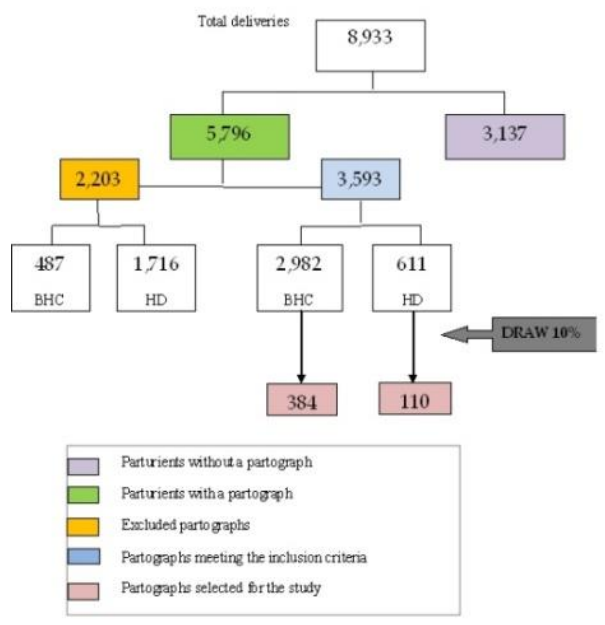

Figure 2: Distribution of maternal care wards according to the use of partograph.

\section{Estimation of maternal and neonatal outcomes}

Among the 494 studied partographs, only 15 mothers were referred to a higher level of care. In this study, we have observed a $9.1 \%$ rate of non-spontaneous deliveries, requiring the use of vacuum extractor, forceps or an episiotomy.

Generally, 33 out of 384 (8.6\%) of the studied cases have crossed the alert line in BHC, against 12 out of 110 $(10.9 \%)$ in $\mathrm{DH}$. But for both health facilities types, parturients younger than 24 years old are most likely to cross the alert line until they reach the action line. Eight cases have crossed the action line $(2.0 \%)$ in BHC, with a referral rate of $75 \%$ (Tables 1 and 2 ).

The interview of the health care providers revealed that lack of equipment and information/training are the main points requiring actions towards a hoped improvement for a suitable environment which would promote parturients care.

Table 1: Distribution of traceability of the labour course according to relationship between management and age bracket at BHC level.

\begin{tabular}{|c|c|c|c|c|c|c|c|}
\hline \multirow{3}{*}{ Age (years) } & \multirow{3}{*}{$\mathbf{n}$} & \multicolumn{3}{|c|}{ To the right of the alert line } & \multicolumn{3}{|c|}{ Upon the action line } \\
\hline & & \multirow{2}{*}{$\begin{array}{l}\text { Traceability } \\
\text { yes }\end{array}$} & \multicolumn{2}{|c|}{ Referral } & \multicolumn{2}{|c|}{ Traceability } & \multirow{2}{*}{$\begin{array}{l}\text { Referral } \\
\text { yes }\end{array}$} \\
\hline & & & n & $\% \mathbf{P M} *$ & yes & $\% \mathrm{PM}$ & \\
\hline $15-19$ & 74 & 8 & 1 & 10,0 & 2 & 25,0 & 1 \\
\hline $20-24$ & 129 & 13 & 5 & 50,0 & 3 & 37,5 & 3 \\
\hline $25-29$ & 90 & 5 & 1 & 20,0 & 1 & 12,5 & 1 \\
\hline $30-34$ & 49 & 2 & & 0,0 & 1 & 12,5 & 1 \\
\hline$\geq 35$ & 42 & 5 & 2 & 20,0 & 1 & 12,5 & \\
\hline Subtotal & 384 & 33 & 9 & 20,4 & 8 & 100,0 & 6 \\
\hline
\end{tabular}

*\% PM: proportion of managements

Table 2: distribution of traceability of the labour course according to relationship between management and age bracket at DH level.

\begin{tabular}{|llllll|}
\hline & & \multicolumn{2}{l}{$\begin{array}{l}l \\
\text { On the right of alert line }\end{array}$} & \multicolumn{2}{l|}{ Upon the action line } \\
\cline { 3 - 6 } & & $\mathbf{n}$ Traceability & Referral & Traceability & Referral \\
\hline $15-19$ & 25 & 4 & $\mathbf{n}$ & 0 & 0 \\
\hline $20-24$ & 40 & 4 & 0 & 0 & 0 \\
\hline $25-29$ & 22 & 3 & 0 & 0 & 0 \\
\hline $30-34$ & 15 & 0 & 0 & 0 & 0 \\
\hline$\geq 35$ & 8 & 1 & 0 & 0 & 0 \\
\hline Subtotal & 110 & 12 & 0 & 0 & 0 \\
\hline
\end{tabular}




\section{DISCUSSION}

In this study, we observed that partograph use has a positive impact on maternal and neonatal delivery-related outcomes. No maternal or perinatal death has been recorded among the 5.796 deliveries monitored with a partograph. However, the numbers of maternal deaths and neonate deaths among deliveries which were not monitored with the partograph $(n=2.517)$ are respectively 5 and 29. This report has also been proved in a study at a maternity hospital in Niamey, Niger: no death case has been reported after the introduction of the partograph there. ${ }^{11}$

Nevertheless, the partograph does not always eliminate all maternal and neonate deaths cases, as shown by the study conducted in Mali in 2005. There, neonatal death rate rose up to 8.5 per 1000 inspite of partograph use. ${ }^{12}$

In $\mathrm{BHC}, 8.6 \%$ of studied deliveries crossed the alert line with a referral rate of $30.3 \%$, and $2.1 \%$ reached the action line with a referral rate of $75 \%$. In $\mathrm{DH}, 10.9 \%$ have crossed the alert line. That rate can be compared with the rate found in Mali, ${ }^{12}$ where crossing the alert line rate among all deliveries equals $42.2 \%$ and crossing the action line rate equals $52.3 \%$.

A $9.1 \%$ rate of non-spontaneous deliveries requiring instrumental operations has also been observed in this study. This rate of dystocia exceeds Bamba's rate $(0.13 \%){ }^{13}$ On the contrary, another study reported a $2 \%$ rate (29 cases) of dystocia. ${ }^{14}$ Dystocia yields among the 5 main causes of maternal mortality in most developing countries, even though their importance varies from one region to another. An abnormally prolonged labour and its consequences are with certainty important factors of maternal and neonatal mortality and morbidity globally. ${ }^{15}$

The 494 partographs we studied allowed us to identify 128 abnormalities during labour, 94 of which were found among primiparas and 34 among women of other categories. Let us remind that the proportion of prolonged labour according to parity is not significative (48.9 vs 47.1, $\mathrm{p}>0.05)$. Yet, Friedman's theories assert that prolonged labour is more frequent in primiparas than in multiparas. $^{16}$

The study found out a non negligible proportion of "small girls". Sure enough, 11 women $(2.3 \%)$ are less than 1.50 metres tall. Among them, 4 belong to the 15 to 19 years age bracket, and 4 others to the 20 to 24 years. In Madagascar, according to the Social and Demographic Survey conducted in 1997, 17.7\% of adolescents aged 15 to 19 have their first sexual intercourse at the age of 15 , making up $13 \%$ of the total fertility rate. ${ }^{17}$ Moreover, female adolescents aged 15 to 19 are two times more at risk of death during pregnancy or delivery than women aged 20 to 29; and if younger than 15 years old, risks are five times higher. ${ }^{18}$

The difference between well managed abnormalities proportions at $\mathrm{BHC}$ and $\mathrm{DH}$ levels could only be the reflection of the health system in Madagascar. Adequate infrastructure is all found in hospitals (DH) comparing to the situation in BHC. ${ }^{19}$

The partograph use rate of $64.8 \%$ still proves to be low enough compared to the results of the assessment of partograph use in Bénin and Mali (respectively $98 \%$ and $100 \%)^{12}$

The interview of the health care providers on the "Actions for wished improvement of the environment" has revealed that lack of materials (such as sphygmomanometer, thermometer, Pinard stethoscope) is the main barrier to the achievement of their work, and then to the filling of the partograph form.

It was also observed that 20 health care providers $(74 \%)$ out of 27 attending birth have been trained: $11(40 \%)$ have had an initial training of more than 2 years, and 9 have had a continuing education. In DH, 8 (72.7\%) health care providers out of 11 attending birth have had training, only one had an initial training, and 7 had a continuing education.

Health care agents attend birth according to their knowledge, as their training on partograph date from many years ago. A similar study showed that health care providers do not know how to fill the partograph form despite the training they have received. As partograph was not part of their initial training, they prefer relying on their experiences. To fill the form, a sphygmomanometer is most needed, but unfortunately not available. ${ }^{20}$

Health care providers' interview gave the evidence of $16.6 \%$ of them not knowing the definition of a partograph. Yet, the study identified a higher knowledge level as well as good practices among midwives regarding partograph use. Health care providers attend births as a work routine without really knowing the benefits of partograph use.

Another article noticed that without regular and tight supervision, accurate annotations when filling out the partograph form fails. The partograph is often filled after delivery just to please any possible supervisor. An unmotivated health care provider would transfer a labouring woman instead of attempting any action that would compel him to monitor and keep watch over this initiative. $^{11}$

In addition to it, decision-making strongly depends on the health care provider's competence and willingness. Lack 
of competence results in an imprecise and badly kept partograph, wrong decisions and transfers. ${ }^{9}$

Assessment of Obstetrical and Neonatal Emergency Care in Madagascar brought the evidence of failures in setting up guidelines for self-apprenticeship at work, and in following up the filling of management tools for partograph use and correct management. ${ }^{21}$

Lack of human resources in BHC and DH is mentioned as the cause of not using the partograph. Sometimes, health facilities receive numerous labouring parturients at the same time, whereas there can be no deliveries at all at times though the admission of women remains unpredictable. Thus, health care providers must always get organized to ensure a skilled attendance in health facilities.

Bad estimation of needs (44.4\%) and absence of delivery in spite of preceding order $(55.6 \%)$ are the main reasons for not using the partograph. As for Bénin, the partograph was regularly used. An interruption of its use was only seen during 5 to 42 days.

Yet, the study found out that an environment described as suitable does not determine accurate use of the partograph. Skilled attendance requires skilled stakeholders, enough materials and technical board, as well as efficient communication and referral systems. ${ }^{22}$ This theory differs from the results of our study. Consequently, Madagascar has to face the great challenge of making the most out of the limited resources in order to improve women and child health.

\section{CONCLUSION}

Although implementation of the partograph appears to be easy and inexpensive, its use still collides with huge difficulties. A partograph accurately used allows improvement of labour management and pregnancy outcome at BHC level, and much more at hospital level. But it requires a qualified attendance and a suitable environment to have a positive and significant impact on maternal and neonatal mortalities related to birth.

\section{ACKNOWLEDGEMENTS}

The authors would like to acknowledge health care providers who willingly participated in this survey.

\section{Funding: None}

Conflict of interest: None declared

Ethical approval: Not required

\section{REFERENCES}

1. Lawn J. 1.16 million neonatal deaths in Africa: How can we save lives through existing programmes? AIP/UNAPSA/PAN/Abuja meeting Nigeria:
October 2006. The Lancet Neonatal Survival 2005: 9-12.

2. OMS, UNICEF, UNFPA, BanqueMondiale. Analyse etinterprétation des estimations de 2005. In: Mortalitématernelle en 2005: estimations de l'OMS, l'UNICEF, l'UNFPAet la Banquemondiale. Editions de l'OMS, Genève; 2008:16-19.

3. Hill K, Thomas K, AbouZahr C, Walker N, Say L, Inoue $\mathrm{M}$ et al. Estimates of maternal mortality worldwide between 1990 and 2005: an assessment of available data. Lancet. 2007;370:1311-19.

4. Hyder AA, Wali SA, McGuckin J. The burden of disease from neonatal mortality: a review of South Asia and Sub-Saharan Africa. BJOG 2003; 110:894901.

5. United Nations. The Millennium Development Goals Report. New York: United Nations Department of Economic and Social Affairs; 2009.

6. INSTAT, EnquêteDémographique de Santé à Madagascar EDSMD III. 2003-2004. Antananarivo: Institut National de Statistique; 2004:442.

7. Barrère $\mathrm{B}$, Barrère $\mathrm{M}$. Mortalitématernelle. In: Enquête Démographiqueet de Santé de Madagascar 2008-2009. Antananarivo: INSTAT and ICF Macro; 2010:221-28.

8. World Health Organization. The partograph: a managerial tool for the prevention of prolonged labour. The principle and strategy. A user's manual. Facilitator's guide. Guidelines for operations research on the application of the partograph. WHO/MCH, 1989; Section 1; 2; 3; 4.

9. Masson El. The partogram: a well-known tool useful for assessing quality of obstetric care. $\mathrm{Br} \mathbf{J}$ Obstet Gynaecol 2007;36:2-7.

10. Bouyer J, Hémon D, Cordier S, Derriennic F, Stücker I, Stengel B et al. Epidémiologie : Principes et méthodes quantitative. Paris: INSERM; 1995: 498.

11. De Groof D, Vangeenderhuysen C, Juncker T, Favi RA. Impact of the introduction of a partogram on maternal and perinatal mortality. Study performed in a maternity clinic in Niamey, Niger. Ann Soc Belg Med Trop 1995;75:321-33.

12. Diarra I, Camara S, Maiga MK. Assessment of the use of partogram at the districte maternity hospital of commune II in Bamako area. Mali Med 2009;2:10.

13. Bamba M. Etude critique des paramètres du partogramme dans le centre de santé de référence de la commune V de 1994-1995 à propos de 3878 cas. Thèse de Doctorat en Médecine $\mathrm{n}^{\circ}$ 52. Bamako; 1998.

14. World Health Organization.Laprévention des anomalies dans la durée du travail: Partie IV: Principes de rechercheopérationnelle. WHO/FHE/MSM, 1993;11.

15. Prual A. La réduction de la mortalitématernelle dans les pays en développement:Théorie et pratique. Med Trop 2004;64:569-75. 
16. Friedman E, Neff RK. Labor and delivery: impact on offspring. Littlton: PSG Publishing Company; 1987.

17. Institut National de Statistique. Enquête Démographiqueet de Santé 1997-1998. Institut National de Statistique, 1998.

18. ONU. Nous, les enfants: examen de fin de décennie du suivi de la Conférencemondiale pour les enfants: Rapport du Secrétairegénéral (A/S-27/3). New York: ONU; 2001

19. MINSANPFPS. Plan de Développement du Secteur Santé et de la Protection Social. Antananarivo: MINSANPFPS;2007:23.
20. Jaffré Y. La bataille des femmes. Afrique de l'Ouest. Faustroll Descartes;2009:200.

21. UNFPA. Evaluation des besoins en matière de soins obstétricaux et néonatales d'urgence à Madagascar. Antananarivo: UNFPA, 2010.

22. Graham WJ, Bell JS, Bullough Colin HW. L'assistance qualifiée à la naissance peut-elle réduire la mortalité maternelle dans les pays en développement? Scotland;2010:30.

DOI: $10.5455 / 2320-1770 . i j r \operatorname{cog} 20130901$

Cite this article as: Rakotonirina JEC,

Randrianantenainjatovo $\mathrm{CH}$, Vololonarivelo BEE, Dorasse R, Rakotomanga JDM, Rakotovao AH. Assessment of the use of partographs in the region of Analamanga. Int J Reprod Contracept Obstet Gynecol 2013;2:257-62. 